\title{
Proteção social na América Latina e Caribe: mudanças, contradições e limites
}

\author{
Social protection in Latin America and the \\ Caribbean: changes, contradictions, and limits \\ Protección social en Latinoamérica y Caribe: \\ cambios, contradicciones y límites
}

\author{
Ana Luiza d'Avila Viana 1 \\ Ana Maria Medeiros da Fonseca 2 \\ Hudson Pacifico da Silva 3
}

doi: 10.1590/0102-311X00216516

\section{Resumo}

Estudos recentes sugerem que os governos da maioria dos países da América Latina e Caribe foram capazes de ampliar os investimentos sociais e introduzir inovações nas politicas de proteção social nas duas últimas décadas, com resultados positivos em termos de cobertura e impacto das ações. Entretanto, as restrições impostas pelo atual cenário de crise fiscal, juntamente com a ascensão de governos ideologicamente mais alinhados com o discurso neoliberal em diversos países da região, apontam para um novo recuo do Estado na área social, comprometendo os avanços obtidos no período recente. O objetivo do texto é discutir as mudanças, contradições e limites dos padrões recentes da proteção social na América Latina e Caribe. A discussão é feita em três itens: descrição da trajetória da proteção social na região, buscando identificar os principais períodos e características da proteção social (benefícios, público-alvo e financiamento); os modelos de proteção social historicamente implantados; e o caso da saúde. Argumentamos que, embora os diferentes países tenham adotado soluções diferenciadas no campo da proteção social, o caráter híbrido das políticas (com grande participação do setor privado no financiamento, oferta e gestão dos serviços) e a prevalência de modelos segmentados (com acesso diferenciado em função da posição social dos indivíduos) têm sido os traços predominantes da proteção social na América Latina e Caribe, limitando as possiblidades de maior equidade e justiça social.

Assistência à Saúde; Política Pública; América Latina; Caribe

\author{
Correspondência \\ H. P. Silva \\ Public Health Research Institute, University of Montréal. \\ Pavillon 7101, Avenue du Parc, bureau 3014-29, Montréal, \\ Quebec, Canada. \\ hp.silva@umontreal.ca \\ 1 Faculdade de Medicina, Universidade de São Paulo, São Paulo, \\ Brasil. \\ 2 Núcleo de Estudos de Políticas Públicas, Universidade Estadual \\ de Campinas, Campinas, Brasil. \\ 3 Public Health Research Institute, University of Montréal, \\ Montréal, Canada.
}

(1)




\section{Introdução}

De acordo com publicações recentes da Comissão Econômica para a América Latina e o Caribe (CEPAL) sobre a situação da proteção social nos países da região 1,2,3, os governos da maioria dos países, em diferentes momentos, foram capazes de ampliar os investimentos sociais e introduzir inovações nas políticas de proteção social nas duas últimas décadas, com resultados positivos em termos de cobertura e impacto das ações. O gasto social público, por exemplo, passou de 12,6\% do Produto Interno Bruto (PIB) no biênio 1991-1992 para 19,5\% no biênio 2013-2014. A maior parte desse aumento está vinculada às áreas de previdência e de assistência social, cujo gasto passou de 5,5\% para 9\% do PIB. Também houve ampliação dos gastos com educação (de 3\% para 4,9\% do PIB) e saúde (de 2,7\% para 4,2\%). Em termos absolutos, o gasto social público mais que dobrou no período, passando de US\$ 801 para US\$ 1.841 por habitante/ano (a preços de 2010).

Com relação aos resultados obtidos, os dados mostram que houve ampliação da cobertura da proteção social em muitas áreas 2: programas de transferência de renda com condicionalidades destinados a famílias em condições de pobreza (de 5,7\% da população total da região no ano 2000 para 21,1\% em 2012); proporção de pessoas com 65 anos e mais que recebem aposentadorias e pensões (de 37\% em 2002 para 41,9\% em 2011); proporção da população ocupada afiliada a um sistema de aposentadoria e pensão (de 46,1\% em 2002 para 55,4\% em 2011); e proporção da população com acesso a serviços de saúde (de 54,4\% em 2002 para 66,4\% em 2012). No que se refere aos indicadores de pobreza, também é possível constatar avanços importantes 3: no período 2002-2014, a proporção de pessoas pobres passou de $43,9 \%$ para $28,2 \%$, e a proporção de pessoas em pobreza extrema passou de $19,3 \%$ para $11,8 \%$.

Cecchini et al. 2 sugerem que tais resultados sinalizam uma mudança no padrão das políticas sociais adotadas na América Latina e Caribe nos anos mais recentes. Esse novo padrão seria distinto da natureza das reformas que foram implantadas nos anos 1980 e 1990, marcadas pela adoção de medidas pró-mercado e de recuo parcial do Estado na área social. A nova situação indicaria um cenário oposto, de crescimento do papel do Estado na proteção social, com ampliação da cobertura e do gasto social.

Esse cenário favorável fez com que alguns autores chegassem a sugerir, mediante a constatação do possível esgotamento do ciclo de hegemonia neoliberal na região, a emergência de um "Estado Neodesenvolvimentista de Bem-Estar Latino-Americano" 4, caracterizado pela retomada do crescimento econômico sob padrões socialmente mais igualitários, a existência de um "desenvolvimentismo distributivo orientado pelo Estado" 5 (p. 779), modelo que confere ênfase ao mercado interno e ao papel do Estado para influenciar a distribuição de renda e a alocação de investimentos, e o surgimento de um período de "institucionalidade neodesenvolvimentista da política social" 6, caracterizada pela adoção de estratégias nacionais de desenvolvimento e uma articulação cada vez maior da política macroeconômica com uma política social capaz de distribuir renda, gerar emprego e inclusão social.

Apesar dos avanços obtidos, algumas críticas pertinentes foram feitas ao modelo social desenvolvimentista implantado em muitos países da América Latina e Caribe. Pochmann 7, por exemplo, ao analisar o fenômeno da mobilidade social ocorrida na base da pirâmide social brasileira dos anos 2000, refuta a ideia de que teria havido uma mudança rumo à constituição de uma sociedade de classe média, em função das características das ocupações geradas no período - de baixa qualificação e baixos rendimentos, com condições de trabalho precárias e grande instabilidade profissional. Lavinas 8 , por sua vez, destaca que as mudanças observadas foram acompanhadas de um processo de “financeirização das políticas sociais”, com deterioração da oferta de serviços públicos e incentivo à mercantilização do acesso, caracterizado pela incorporação de novos grupos sociais ao mercado de consumo de massas mediante o acesso destes grupos aos produtos oferecidos pelo sistema financeiro (crédito direto ao consumidor, planos de saúde, financiamento estudantil etc.) em detrimento de políticas públicas para a proteção contra riscos e incertezas. E Lo Vuolo 9 enfatiza os limites das políticas sociais redistributivas na América Latina e Caribe, em função da escassez de complementariedades positivas entre o sistema econômico, cuja instabilidade representa um problema estrutural na região, e o sistema de proteção social, incapaz de atuar como instrumento anticíclico para manter o bem-estar dos grupos sociais mais vulneráveis. 
$\mathrm{O}$ atual contexto econômico e político da América Latina e Caribe parece mesmo colocar em xeque diagnósticos otimistas. Projeções indicam um cenário de recessão econômica em diversos países da região (Brasil, Argentina, México e Venezuela) e redução do crescimento em muitos outros (Colômbia e Chile), com impactos negativos sobre o mercado de trabalho (aumento das taxas de desemprego, deterioração da qualidade dos postos de trabalho, estagnação dos salários e da formalidade) e a capacidade fiscal do Estado 10. Ao mesmo tempo, a ascensão de governos ideologicamente mais alinhados com o discurso neoliberal em diversos países da região sugere a possibilidade de um novo recuo do Estado na área social e a adoção de um "modelo social liberal privado" 11, comprometendo a continuidade das políticas e programas implantados no período recente.

O objetivo do texto é discutir as mudanças, contradições e limites dos padrões recentes da proteção social, em específico para a saúde, no conjunto dos países da região. O argumento central a ser explorado é que, embora os diferentes países tenham adotado soluções diferenciadas no campo da proteção social, o caráter híbrido das políticas (com grande participação do setor privado no financiamento, oferta e gestão dos serviços) e a prevalência de modelos segmentados (com acesso diferenciado em função da posição social dos indivíduos) têm sido os traços predominantes na América Latina e Caribe, limitando as possibilidades de maior equidade e justiça social. Essa discussão é feita em três itens separados para fins de organização do texto, mas cujos temas estão interligados. O primeiro item descreve, de maneira breve, a trajetória da proteção social na região, buscando identificar os principais períodos e características da proteção social (benefícios, público-alvo e financiamento). Em seguida, com base na abordem dos regimes de proteção social, apresentamos algumas tipologias propostas por diferentes autores para analisar e classificar os distintos modelos de proteção social na América Latina e Caribe. Por fim, o último item foca a discussão no caso da saúde, na tentativa de compreender os principais momentos do desenvolvimento histórico dos sistemas de saúde, assim como os modelos paradigmáticos que servem de guia para as políticas de saúde nos diferentes países da região.

\section{A trajetória da proteção social na América Latina e Caribe}

A literatura especializada sobre o tema 12,13,14,15,16 destaca que os modernos sistemas de proteção social, regulados por normas nacionais e voltados para cobrir riscos padronizados (acidentes, doenças, velhice, morte e desemprego) para faixas cada vez mais amplas de pessoas e categorias profissionais, de natureza obrigatória para grupos populacionais e/ou poder público, com financiamento múltiplo (Estado, empresários e trabalhadores) e reconhecimento dos benefícios como direitos, surgiram nas sociedades capitalistas europeias no final do século XIX, se consolidaram durante o século XX, especialmente após a 2a Guerra Mundial, e entraram num período de crise e reformas a partir da década de 1970. Condicionantes de ordem econômica (industrialização e necessidade de acumulação de capital) e de ordem político-institucional (ampliação de direitos, acordos envolvendo capital e trabalho, mobilizações da classe trabalhadora e configurações históricas particulares de estruturas estatais e instituições políticas) ajudam a explicar a origem e o desenvolvimento dos sistemas de proteção social nos países centrais 17 .

De modo geral, diversos autores $18,19,20,21,22$ concordam que a trajetória da proteção social na América Latina está relacionada com os diferentes modelos de desenvolvimento que foram historicamente implantados na região. Filgueira 23 , em trabalho recente, identifica quatro grandes períodos que sinalizam diferentes características de atuação do Estado Social na América Latina e Caribe, vinculados a distintas etapas do desenvolvimento latino-americano: o Estado Social minimalista do período primário exportador (1870-1930); o Estado Social de base contributiva durante o modelo de substituição de importações (1930-1980); a inflexão rumo ao Estado Social refratário e à incorporação do mercado na área social, própria da era neoliberal (1980-2000); e o Estado Social renovado dos anos 2000, que combinaria critérios de necessidade, contribuição e cidadania inseridos num modelo aberto e de orientação exportadora. A Tabela 1 sintetiza as principais características relacionadas aos benefícios, ao público-alvo e ao financiamento em três setores-chave da proteção social - previdência e assistência social, saúde e educação - em cada um dos diferentes períodos de desenvolvimento da América Latina e Caribe. 
Tabela 1

Benefícios, público-alvo e financiamento para três setores da proteção social em diferentes períodos de desenvolvimento na América Latina e Caribe.

\begin{tabular}{|c|c|c|c|c|}
\hline Setor & $\begin{array}{l}\text { Estado Social } \\
\text { do liberalismo } \\
\text { oligárquico- } \\
\text { exportador } \\
(1870-1930)\end{array}$ & $\begin{array}{l}\text { Estado Social } \\
\text { do modelo de } \\
\text { substituição de } \\
\text { importações } \\
\text { (anos 1930-1980) }\end{array}$ & $\begin{array}{l}\text { Estado Social do modelo } \\
\text { liberal exportador } \\
\text { (anos 1980-1990) }\end{array}$ & $\begin{array}{l}\text { Estado Social do modelo } \\
\text { estatal exportador } \\
\text { (anos 2000) }\end{array}$ \\
\hline \multirow[t]{3}{*}{$\begin{array}{l}\text { Previdência e assistência } \\
\text { social }\end{array}$} & $\begin{array}{l}\text { Benefícios: seguro } \\
\text { de saúde, doença e } \\
\text { aposentadoria. }\end{array}$ & $\begin{array}{c}\text { Benefícios } \\
\text { contributivos: } \\
\text { aposentadorias e } \\
\text { pensões por invalidez, } \\
\text { sobrevivência } \\
\text { e acidentes de } \\
\text { trabalho. Benefícios } \\
\text { não contributivos: } \\
\text { transferências } \\
\text { baseadas em } \\
\text { determinações dos } \\
\text { meios de vida ou } \\
\text { provas de meios. }\end{array}$ & $\begin{array}{l}\text { Benefícios contributivos: } \\
\text { dependentes do } \\
\text { modelo de capitalização } \\
\text { individual. Benefícios não } \\
\text { contributivos: transferências } \\
\text { baseadas em determinações } \\
\text { dos meios de vida ou provas } \\
\text { de meios. }\end{array}$ & $\begin{array}{c}\text { Benefícios contributivos: } \\
\text { inclusão de modelos não } \\
\text { contributivos e flexibilização } \\
\text { de critérios contributivos. } \\
\text { Benefícios não } \\
\text { contributivos: ampliação } \\
\text { das transferências } \\
\text { condicionadas. }\end{array}$ \\
\hline & $\begin{array}{c}\text { Público-alvo: militares, } \\
\text { funcionários públicos, } \\
\text { professores e, } \\
\text { em alguns casos, } \\
\text { profissionais liberais. }\end{array}$ & $\begin{array}{c}\text { Público-alvo: } \\
\text { funcionários públicos, } \\
\text { setores médios } \\
\text { e trabalhadores } \\
\text { formais (benefícios } \\
\text { contributivos). } \\
\text { Pobres e população } \\
\text { urbana informal (não } \\
\text { contributivos). }\end{array}$ & $\begin{array}{l}\text { Público-alvo: setores } \\
\text { médios, médios-altos e } \\
\text { altos formais (benefícios } \\
\text { contributivos). População } \\
\text { pobre e população rural } \\
\text { (não contributivos). }\end{array}$ & $\begin{array}{l}\text { Público-alvo: setores } \\
\text { médios, médios-baixos } \\
\text { e baixos (benefícios } \\
\text { contributivos). Famílias } \\
\text { pobres e vulneráveis e } \\
\text { população rural com filhos } \\
\text { (não contributivos). }\end{array}$ \\
\hline & $\begin{array}{l}\text { Financiamento: } \\
\text { impostos gerais } \\
\text { (inicialmente), } \\
\text { poupança e } \\
\text { contribuições. }\end{array}$ & $\begin{array}{l}\text { Financiamento: } \\
\text { contribuições } \\
\text { de empresas e } \\
\text { trabalhadores, } \\
\text { com subsídio do } \\
\text { Estado (benefícios } \\
\text { contributivos). } \\
\text { Impostos gerais (não } \\
\text { contributivos). }\end{array}$ & $\begin{array}{c}\text { Financiamento: } \\
\text { contribuições de empresas e } \\
\text { trabalhadores, com subsídio } \\
\text { do Estado para transição } \\
\text { de modelos (benefícios } \\
\text { contributivos). Impostos } \\
\text { gerais (não contributivos). }\end{array}$ & $\begin{array}{l}\text { Financiamento: impostos } \\
\text { gerais para modelos não } \\
\text { contributivos e subsídios } \\
\text { cruzados ou impostos } \\
\text { gerais para modelos } \\
\text { contributivos. }\end{array}$ \\
\hline
\end{tabular}

(continua)

O período do liberalismo oligárquico-exportador, no qual a maioria dos países da América Latina e Caribe se incorporou à economia global mediante um modelo exportador de matérias-primas e importador de bens de consumo acabados e bens de capital, correspondeu à gênese do Estado Social na América Latina. A expansão da educação laica e de base estatal, a atuação cada vez mais ampla das autoridades sanitárias no campo da saúde e os primeiros sistemas previdenciários e de seguro do trabalho (destinados predominantemente aos trabalhadores civis e militares do Estado) representam as três novidades mais importantes da política social no período 23 .

O período seguinte, do modelo de substituição de importações, representa uma nova etapa de desenvolvimento na região, impulsionada pela crise econômica dos anos 1930 e seus efeitos negativos sobre o balanço de pagamentos. Nessa etapa, o Estado assumiu papel central no desenvolvimento econômico e social, mediante a adoção de diversas medidas destinadas a incentivar o crescimento das indústrias orientadas ao mercado interno e, desta forma, substituir boa parte dos bens importados 
Tabela 1 (continuação)

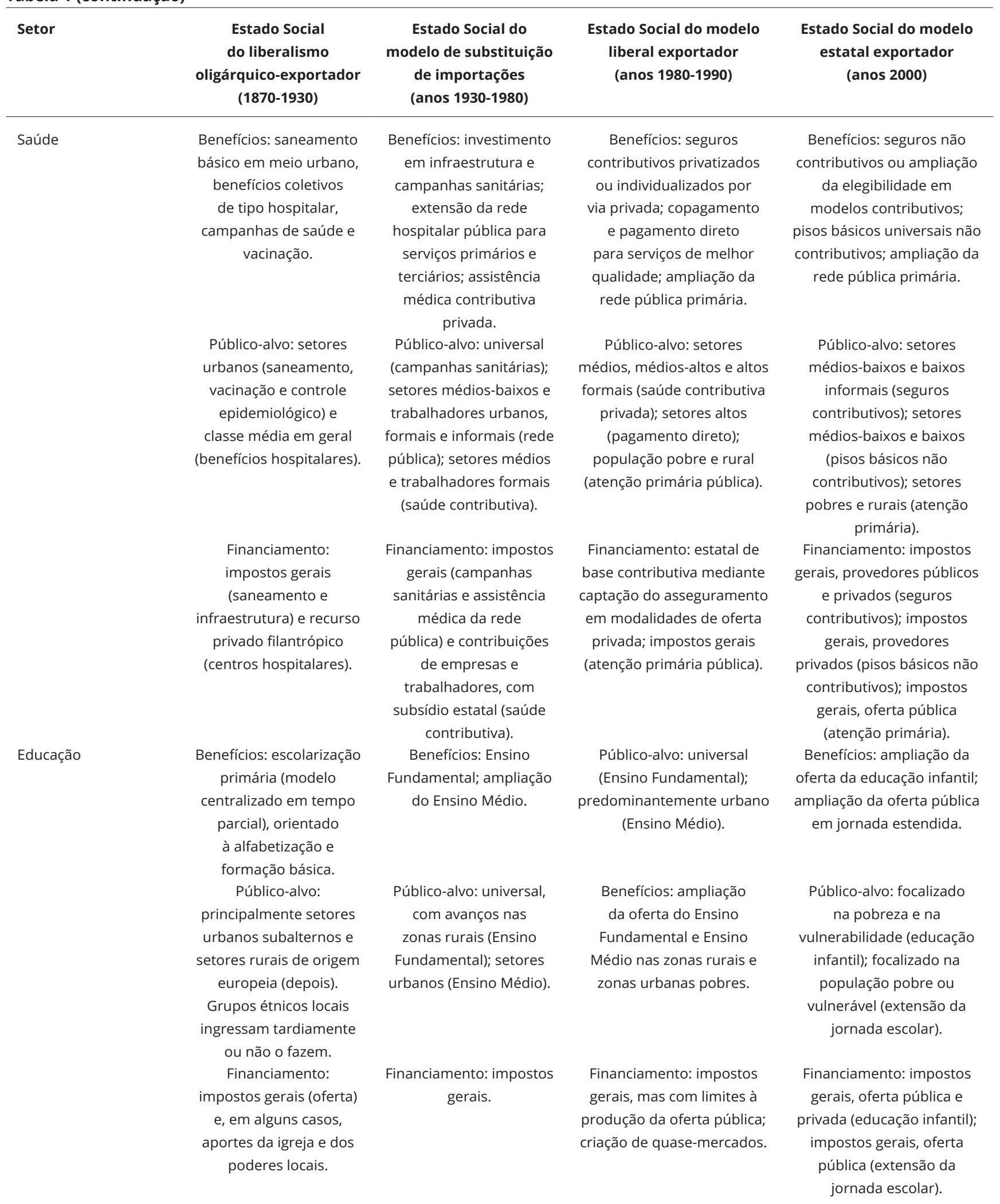

Fonte: adaptado de Filgueira 23. 
pela produção doméstica 24,25. Do ponto de vista da proteção social, é nesse período que se adotam legislações para regular os direitos trabalhistas, ao mesmo tempo em que se massifica o sistema educacional primário, com avanços nos demais níveis de educação. Sistemas de saúde duais, que combinam serviços prestados tanto na esfera pública como no segmento previdenciário contributivo são criados, enquanto sistemas de aposentadorias e pensões são consolidados. O Estado Social desse período está inserido em sociedades cada vez mais industrializadas e urbanizadas, com estruturas familiares tradicionais, mas com pressões políticas crescentes dos setores médios e dos trabalhadores urbanos, de modo que os benefícios são direcionados majoritariamente para estes grupos sociais 23 . Trata-se de uma cidadania regulada e estratificada, cujos direitos estão atrelados à condição de trabalhador da economia formal, com pouco ou nenhum avanço para os setores subalternos rurais e trabalhadores informais urbanos 26 .

A perda de dinamismo do modelo de substituição de importações, em função da grave crise que atingiu os países da região a partir da década de 1970, abriu espaço para o terceiro período de desenvolvimento, marcado pela adoção de programas de ajuste estrutural na economia e pelo recuo da atuação do Estado na área social. Num contexto de grandes restrições fiscais e limitada capacidade de gasto do Estado, as políticas sociais passaram a contar com as seguintes características 23: sistemas de asseguramento com capitalização individual (no lugar dos sistemas contributivos de repartição simples); políticas sociais focalizadas nos grupos mais pobres (no lugar de políticas universais); descentralização da administração e da tomada de decisão (no lugar de modelos centralizados); políticas sociais baseadas na demanda (no lugar de políticas baseadas na oferta); e incorporação de provedores privados e mecanismos de competição administrada. Destaque-se que essas características integravam (e integram) uma determinada agenda internacional para as políticas sociais, formada pela oferta de ideias produzidas por agências que compõem a comunidade internacional de ajuda ao desenvolvimento. No caso da saúde, por exemplo, diversas recomendações sobre as reformas dos sistemas de saúde e das próprias atribuições do Estado no setor foram formuladas pelo Banco Mundial e pela Organização Mundial da Saúde (OMS) nesse período, no intuito de disciplinar as políticas dos países em desenvolvimento, os quais deveriam implantar tais reformas para ter acesso aos recursos destas agências 27.

A partir dos anos 2000, um novo cenário econômico marcado pela expansão dos mercados asiáticos resultou no aumento da demanda por produtos primários, das rendas com as exportações destes produtos e fluxos crescentes de capitais, propiciando maior crescimento econômico e disponibilidade de recursos fiscais, o que permitiu a ampliação do gasto público na região. É nesse período que o Estado ressurge como ator renovado no processo de desenvolvimento socioeconômico na América Latina e Caribe, mediante a adoção de uma política fiscal expansionista e redistributiva, novas formas de regulação estatal e políticas sociais destinadas a aumentar a cobertura da proteção social. Também é nesse período que os benefícios assistenciais não contributivos, como os programas de transferência de renda condicionada, adquirem centralidade em muitos países da região e passam a constituir um dos principais mecanismos de combate à pobreza 28 . Tudo isso contribuiu para redefinir, mais uma vez, as fronteiras entre o contributivo e o não contributivo, o focalizado e o universal, o público e o privado.

Embora esse tipo de periodização ajude a identificar os aspectos gerais da estruturação da proteção social nos países da região, pelo menos três observações devem ser feitas. Em primeiro lugar, as fronteiras na área social não são tão nítidas em cada período, na medida em que a política social na América Latina e Caribe sempre manteve níveis elevados de hibridismo, combinando traços dos modelos corporativo (voltado para o mercado formal), liberal (voltado para a massa de excluídos) e universal (com base no direito de cidadania). Em segundo, como será visto no item seguinte, não se pode falar de um modelo único de proteção social predominante na América Latina e Caribe, em função da grande heterogeneidade entre os países da região, o que implicou a adoção de respostas também diferenciadas no campo social dentro de um mesmo período de desenvolvimento. E por último é necessário questionar em que medida o último período sugerido por Filgueira 23 ainda faz sentido em função das mudanças políticas e econômicas que estão afetando diversos países da região nos anos mais recentes, com implicações diretas sobre as formas de atuação do Estado na área social. 


\section{Regimes de proteção social}

Estudos comparativos sobre os sistemas de proteção social nos países desenvolvidos foram realizados por diversos autores com base na abordagem dos regimes de proteção social, que permite conceituar tipologias para classificar os países em função de suas similaridades e diferenças. A tipologia proposta por Esping-Andersen 29 para um conjunto de países da Organização para a Cooperação e Desenvolvimento Econômico (OCDE), inspirada no trabalho clássico de Titmuss 30 , permanece emblemática e tem servido de referência para diversos trabalhos posteriores, que a tem validado, desafiado ou expandido $31,32,33$. Baseada no grau em que indivíduos ou famílias podem manter um padrão de vida socialmente aceitável independente da sua participação no mercado (desmercantilização das relações sociais), a tipologia de Esping-Andersen identifica a existência de três modelos ideais: o regime socialdemocrata dos países escandinavos, o conservador/corporativista da Europa continental, e o regime liberal dos países anglo-saxões, cada um deles com importância distinta para o papel desempenhado pelas três principais instituições que historicamente se ocupam da proteção social - Estado, família e mercado 29.

Tipologias sobre os regimes de proteção social nos países da América Latina, que têm características históricas, culturais e socioeconômicas que diferem substancialmente daquelas observadas nos países desenvolvidos, também foram propostas. Sínteses analíticas dessas tipologias podem ser consultadas em diversos trabalhos publicados no período recente 34,5,36,37. Para os propósitos deste artigo, selecionamos as classificações propostas por cinco autores, em função das diferenças em termos de contexto histórico, dimensões de análise e agrupamentos resultantes (Tabela 2). Os regimes propostos por Mesa-Lago 38 e Filgueira 39 se baseiam nos sistemas de proteção social consolidados durante o período de substituição de importações, já as classificações de Franzoni 40, Cecchini et al. 2 e Cantu 37 consideram as reformas implantadas nos períodos mais recentes.

O estudo comparativo de Mesa-Lago 38 em vinte países da América Latina utilizou 11 indicadores para sinalizar a antiguidade de implantação e o grau de desenvolvimento dos sistemas de seguridade social. $\mathrm{O}$ autor identificou três grupos de países: pioneiros-alto, intermediários e tardios-baixo. Os resultados obtidos por Mesa-Lago indicam que os países pioneiros contam com sistemas previdenciários mais antigos, percentual mais elevado da população coberta, maiores níveis de contribuição sobre a folha de pagamentos, maior gasto social como percentual do PIB, maior proporção do gasto social destinado a aposentadorias, maior desequilíbrio financeiro, maior proporção de pensionistas em relação aos contribuintes, maior percentual de idosos na população e maior expectativa de vida ao nascer 38 .

A tipologia desenvolvida por Filgueira ${ }^{39}$ propõe classificar os diferentes países da região em três grupos, considerando as políticas sociais do Estado (cobertura, benefícios e requerimentos) e a estratificação social resultante: universalismo estratificado, no qual a maior parte da população encontra-se coberta pelos sistemas previdenciário, de saúde e de educação, mas com acesso diferenciado em função da inserção no mercado de trabalho; dual, prevalente em países com grande heterogeneidade territorial e que, por isto mesmo, têm regiões onde a proteção social está mais desenvolvida e regiões com grande desproteção e baixa incorporação da maior parte da população ao sistema; e excludente, caracterizado por sistemas elitistas nos campos da previdência e da saúde, com acesso privilegiado para um número reduzido de trabalhadores formais e funcionários públicos, e um sistema dual em matéria de educação.

A terceira tipologia, apresentada por Franzoni 40, baseia-se em dados disponíveis para 18 países da região e agrupados em três dimensões - mercantilização, desmercantilização e desfamiliarização. Utilizando-se o método estatístico de análise de clusters, a autora identifica a existência de três grupos: estatal focalizado, com cobertura estatal focalizada nos pobres e maior financiamento individual da proteção social; estatal estratificado, no qual as políticas sociais do Estado atingem mais os trabalhadores da economia formal e o financiamento da proteção social é mais coletivo; e informal familiarista, com alta informalidade do trabalho, políticas públicas residuais e centralidade das famílias na proteção social.

No âmbito dos trabalhos desenvolvidos pela CEPAL no período recente, o estudo comparativo de Cecchini et al. 2 chama a atenção por enfatizar a extensão das lacunas de bem-estar (welfare gaps) nos diferentes países da América Latina. Apoiando-se no trabalho desenvolvido por Uthoff et al. ${ }^{41} \mathrm{e}$ utilizando o método estatístico de análise de conglomerados hierárquicos, os autores identificaram três grupos de países: lacunas pequenas de bem-estar, contemplando países mais ricos, com menores 


\section{Tabela 2}

Regimes de proteção social na América Latina e Caribe segundo diferentes autores.

\begin{tabular}{|c|c|c|c|}
\hline Autor/Ano & Dimensões de análise & Grupos & Exemplos de países \\
\hline \multirow[t]{3}{*}{ Mesa-Lago 38/1986 } & $\begin{array}{l}\text { Antiguidade da implantação do } \\
\text { sistema de proteção social e nível de }\end{array}$ & Pioneiros: alto desenvolvimento. & $\begin{array}{l}\text { Uruguai, Argentina, Chile, Cuba, } \\
\text { Brasil e Costa Rica. }\end{array}$ \\
\hline & desenvolvimento do sistema. & $\begin{array}{l}\text { Intermediários: médio } \\
\text { desenvolvimento. }\end{array}$ & $\begin{array}{c}\text { Panamá, México, Peru, Colômbia, } \\
\text { Bolívia, Equador, Paraguai e } \\
\text { Venezuela. }\end{array}$ \\
\hline & & Tardios: baixo desenvolvimento. & $\begin{array}{l}\text { República Dominicana, } \\
\text { Guatemala, El Salvador, } \\
\text { Nicarágua, Honduras e Haiti. }\end{array}$ \\
\hline \multirow[t]{3}{*}{ Filgueira 39/1998 } & Grau de cobertura das políticas sociais do & Universalismo estratificado & Argentina, Chile e Uruguai. \\
\hline & Estado e informalidade. & Dual. & Brasil e México. \\
\hline & & Excludente. & $\begin{array}{c}\text { Guatemala, Honduras, El Salvador } \\
\text { e Nicarágua. }\end{array}$ \\
\hline \multirow[t]{2}{*}{ Franzoni 40/2008 } & $\begin{array}{c}\text { Graus de mercantililzação, } \\
\text { desmercantilização e desfamiliarização. }\end{array}$ & $\begin{array}{l}\text { Estatal produtivista. } \\
\text { Estatal protecionista. }\end{array}$ & $\begin{array}{c}\text { Argentina e Chile. } \\
\text { Brasil, Uruguai, Costa Rica e } \\
\text { México. }\end{array}$ \\
\hline & & Informal familiarista. & Demais países. \\
\hline \multirow[t]{3}{*}{ Cecchini et al. 2/2014 } & $\begin{array}{l}\text { Capacidade societal de gerar renda } \\
\text { via mercado; capacidade estatal de }\end{array}$ & $\begin{array}{l}\text { Lacunas pequenas na proteção } \\
\text { social. }\end{array}$ & $\begin{array}{c}\text { Argentina, Brasil, Costa Rica, Chile, } \\
\text { Panamá, Uruguai, Venezuela. }\end{array}$ \\
\hline & $\begin{array}{c}\text { prover sustento; proteção para grupos } \\
\text { vulneráveis. }\end{array}$ & $\begin{array}{l}\text { Lacunas intermediárias na } \\
\text { proteção social. }\end{array}$ & $\begin{array}{c}\text { Colômbia, Equador, México, Peru } \\
\text { e República Dominicana. }\end{array}$ \\
\hline & & $\begin{array}{l}\text { Lacunas grandes na proteção } \\
\text { social. }\end{array}$ & $\begin{array}{c}\text { Bolívia, El Salvador, Honduras, } \\
\text { Guatemala e Nicarágua. }\end{array}$ \\
\hline \multirow[t]{4}{*}{ Cantu 37/2015 } & $\begin{array}{l}\text { Grau em que a proteção social deriva } \\
\text { do Estado; grau de mercantilização }\end{array}$ & Liberal moderado. & $\begin{array}{c}\text { Argentina, Brasil, Costa Rica e } \\
\text { Uruguai. }\end{array}$ \\
\hline & das políticas sociais; estratégias de & Liberal radical. & Chile e México. \\
\hline & subsistência das famílias. & Excludente familiarista. & $\begin{array}{c}\text { Bolívia, Colômbia, Equador, } \\
\text { Guatemala, Panamá, Paraguai, } \\
\text { Peru e Venezuela. }\end{array}$ \\
\hline & & Excludente migratório. & $\begin{array}{l}\text { El Salvador, Honduras e } \\
\text { Nicarágua. }\end{array}$ \\
\hline
\end{tabular}

taxas de dependência, menos pobreza, maior gasto social e maior proporção da população coberta pela proteção social; lacunas moderadas, com países numa situação intermediária; e lacunas severas, formado por países mais pobres, com altas taxas de dependência e pobreza, baixo gasto social e menor cobertura da proteção social.

Por fim, a classificação proposta por Cantu 37 parte das contribuições do trabalho de Barrientos 42 , que identifica a existência de um movimento geral de transformação do regime de proteção social na América Latina, que estaria lentamente migrando de um modelo conservador-informal (anterior às reformas neoliberais) para um modelo liberal-informal (após as reformas), com maior participação do mercado como regulador da estratificação social. Utilizando indicadores agrupados em três dimensões - grau em que a proteção social deriva do Estado, grau de mercantilização das políticas sociais, e estratégias de subsistência das famílias - quatro grupos de países são identificados: liberal moderado, liberal radical, excludente familiarista e excludente migratório. Os dois primeiros têm maior participação do Estado na proteção social, cobertura estratificada das políticas sociais e importância relativa do mercado nos regimes de previdência privada, educação e saúde, principalmente nos países do grupo liberal radical. Já nos dois últimos grupos o alcance das políticas sociais é menor e a estratificação pela informalidade é maior; a diferença reside nas estratégias adotadas para enfrentar 
as situações de risco social: estratégias familiares tradicionais predominam no grupo excludente familiarista, ao passo que a migração da força de trabalho para o exterior é a principal estratégia adotada nos países do grupo excludente migratório.

Embora cada tipologia enfatize diferentes aspectos, todas elas sinalizam para o fato de que existem diferenças marcantes nas alternativas adotadas para tratar da questão social em cada contexto. Essas diferenças parecem refletir, de um lado, os distintos padrões de modernização sugeridos por Draibe \& Riesco 4 e, de outro, a atuação dos diferentes grupos de pressão identificados por Mesa-Lago 43 , cujo poder determina, em grande medida, o momento em que cada grupo passa a desfrutar dos benefícios do sistema, o grau de cobertura, o custo financeiro e a generosidade dos benefícios. Isso nos remete para o peso da organização política desses grupos na conformação e expansão dos sistemas de proteção social na região, onde não aconteceu um alinhamento entre grupos sindicais e o universalismo, como no caso europeu, tampouco um movimento forte no sentido da inclusão das classes médias em modelos mais expansivos de proteção social, nem mesmo uma clara opção pelos partidos políticos defensores de políticas sociais mais inclusivas.

\section{O caso da saúde}

Num artigo publicado em 1964 sobre atenção médica e classe social na América Latina, Roemer 44 observou que a classe social de uma pessoa da região poderia ser facilmente identificada examinando-se o modo como ela obtém os serviços de atenção à saúde dos quais necessita. Isso porque era possível identificar a existência de uma clara associação entre as principais classes sociais da época e os diferentes padrões e sistemas de atenção à saúde existentes. Segundo o autor, a operação paralela e descoordenada de tais sistemas, que serviam diferentes grupos populacionais nas mesmas cidades e regiões, não apenas gerava as maiores desigualdades de acesso entre estes grupos, mas também grande ineficiência e desperdício.

Trinta anos mais tarde, já no contexto das reformas neoliberais dos anos 1980 e 1990, o texto clássico de Londoño \& Frenk 45 apontava na mesma direção ao sinalizar que a grande maioria dos países latino-americanos tinha um modelo segmentado de sistema de saúde, organizado em três grandes segmentos, no qual diferentes grupos populacionais são atendidos em diferentes instituições. Nesse modelo segmentado, os mais pobres e desempregados dependem da rede de serviços mantida pelo Ministério da Saúde, os trabalhadores assalariados formais acessam os serviços vinculados ao sistema previdenciário contributivo, já o restante da população utiliza os serviços oferecidos pelo setor privado. A principal característica dessa forma de organização do sistema de saúde é, portanto, a segregação horizontal de grupos populacionais em diferentes nichos, com integração vertical de funções (administração, financiamento e provisão de serviços). As implicações negativas desse modelo são bastante conhecidas 45: oferta desigual de benefícios, qualidade dos serviços e proteção financeira para os diferentes grupos populacionais, além da geração de desperdício de recursos e duplicidade de esforços.

Ainda de acordo com Londoño \& Frenk ${ }^{45}$, era possível observar a existência de três modelos de sistema de saúde nos países da América Latina: (i) o modelo público unificado, no qual o Estado financia e fornece os serviços de saúde para toda a população por meio de um sistema único e verticalmente integrado, com pouca ou nenhuma liberdade de escolha (para os usuários) e competição na prestação dos serviços (entre os provedores); (ii) o modelo privado atomizado, caracterizado pela dispersão dos recursos financeiros, provenientes da compra de seguros e planos de saúde ou do pagamento direto pelos serviços, os quais são prestados por múltiplos provedores, sem que estas duas funções estejam integradas verticalmente; e (iii) o modelo contratual público, que combina financiamento público com uma participação crescente do setor privado na prestação de serviços, de modo que estas duas funções estão separadas, mas são viabilizadas por meio de contratos entre o Estado e as organizações privadas.

Apesar do diagnóstico correto, o modelo proposto por esses autores (e recomendado pelas agências internacionais de ajuda ao desenvolvimento) não resultaram necessariamente na melhor integração do sistema de saúde, nem mesmo melhoraram aspectos técnicos (ganhos de eficiência, por 
exemplo), além de privilegiar alguns grupos, manter vazios assistenciais e sobrecarregar a parcela do gasto privado, mediante o incentivo da compra de serviços e a criação e expansão de um forte mercado privado na área assistencial, seja ambulatorial ou de internação ${ }^{46}$. Esse modelo, denominado de pluralismo estruturado, prevê que a administração do sistema seja feita pelo Ministério da Saúde, que assume a responsabilidade pelo planejamento estratégico de todo o sistema por intermédio de regras e incentivos; o financiamento por um ou poucos fundos públicos; e a prestação de serviços inclui a atuação de múltiplos provedores, públicos e privados, sob a supervisão de um órgão regulador. Expandiuse de forma crescente na região baseando-se na experiência da Colômbia nos anos 1990, e teve como contraponto tanto os modelos universais de saúde do Brasil e da Costa Rica como o paradigmático modelo cubano, que influenciou a região no sentido da prioridade à atenção primária, ofertada por profissionais próprios e qualificados para as ações mais prevalentes de saúde.

Apesar das reformas adotadas na América Latina e Caribe no período recente 47 , centradas na organização do sistema de saúde por funções, mudança nas regras de elegibilidade, ênfase na atenção primária e maior integralidade da atenção, incluindo ações voltadas para enfrentar os determinantes sociais da saúde 48 , a maioria dos países da América Latina ainda conta com um modelo segmentado de sistema de saúde. É o que mostra o diagnóstico realizado por Mesa-Lago 49 em 2008 e atualizado por Cotlear et al. 50 em 2015. Dos vinte países analisados, 13 (65\%) continuavam a ter sistemas de saúde segmentados, com separação entre o sistema público e o sistema previdenciário contributivo.

Olhando em retrospectiva histórica, Cotlear et al. 50 sugerem a existência de quatro etapas de desenvolvimento institucional dos sistemas de saúde na América Latina e Caribe (Tabela 3). A primeira etapa, que inicia no século XIX com a independência dos diferentes países da região, representa um momento inicial da estruturação dos sistemas de saúde, com atuação limitada do Estado na saúde pública, predomínio de atividades destinadas à prevenção e ao controle de doenças, serviços assistenciais prestados por instituições religiosas e filantrópicas, e emergência dos primeiros esquemas de saúde de natureza contributiva, principalmente nos países de imigração europeia. A segunda corresponde à criação das instituições nacionais - Ministério da Saúde e instituições previdenciárias - que serviram de base para o modelo segmentado de saúde nas primeiras décadas do século XX. A adoção de legislação nacional para delimitar um segmento da população coberta pelos benefícios contributivos, consolidando assim a segmentação entre trabalhadores do setor formal da economia e os não assalariados e pobres, marca o início da terceira etapa de desenvolvimento institucional dos sistemas de saúde na América Latina e Caribe. Por fim, a quarta etapa iniciou com a integração dos serviços de saúde vinculados ao sistema público e ao sistema contributivo ou com a introdução de ações para equalizar os serviços oferecidos nestes dois segmentos.

Segundo os autores da periodização, experiências tão diferentes como a criação do Sistema Único de Saúde (SUS) no Brasil (1988), o estabelecimento do Seguro Popular no México (2004), a adoção do Acesso Universal com Garantias Explícitas (AUGE) no Chile (2005) e a implantação de planos de benefícios equalizados na Colômbia (2012) ilustram essa última fase. O que a diversidade dessas experiências sugere é que, na verdade, continuam em disputa duas concepções divergentes de sistemas de saúde: uma voltada para o universalismo com base em direitos sociais e assegurada por um sistema único e público de saúde, e outra que prioriza a expansão da cobertura e a redução do risco financeiro das famílias (a que hoje é denominada cobertura universal de saúde), com financiamento misto e fortalecimento das regras de mercado (competição entre provedores).

Embora a concepção de Cobertura Universal de Saúde tenha adquirido grande centralidade no debate internacional nos últimos anos, a ponto de integrar a Agenda 2030 para o Desenvolvimento Sustentável das Nações Unidas, sua origem está vinculada às recomendações do Banco Mundial nos anos 1990, que defendia maior protagonismo dos mecanismos de mercado no setor saúde, e às propostas da OMS nos anos 2000, que reconhecia a incapacidade dos países em desenvolvimento de oferecer atenção integral para todos e sugeria a adoção de um "novo universalismo" na saúde, contemplando a oferta de uma cesta básica de serviços. Diversas críticas foram feitas à proposta de cobertura universal de saúde 51,52,53, enfatizando tanto as limitações do modelo como os resultados observados nos países que implantaram seus princípios e diretrizes na América Latina e Caribe (principalmente Chile, Colômbia e México). 


\section{Tabela 3}

Características das quatro etapas de desenvolvimento institucional dos sistemas de saúde na América Latina e Caribe.

\begin{tabular}{|c|c|c|c|}
\hline $\begin{array}{l}\text { 1a etapa: instituições pré- } \\
\text { nacionais de saúde }\end{array}$ & $\begin{array}{l}\text { 2a etapa: instituições } \\
\text { nacionais de saúde }\end{array}$ & $\begin{array}{l}\text { 3a etapa: atenção primária e } \\
\text { consolidação da segmentação }\end{array}$ & $\begin{array}{l}\text { 4a etapa: superando a } \\
\text { segmentação }\end{array}$ \\
\hline $\begin{array}{l}\text { - Saúde pública reconhecida como } \\
\text { área de intervenção limitada do } \\
\text { Estado, geralmente ligada ao } \\
\text { comércio e ao uso econômico do } \\
\text { território. } \\
\text { - Serviços de atenção à saúde } \\
\text { inicialmente como objeto de } \\
\text { caridade de ordens religiosas, } \\
\text { evoluindo para instituições } \\
\text { beneficentes. } \\
\text { - Atividades de saúde pública } \\
\text { focadas na prevenção e controle de } \\
\text { epidemias. } \\
\text { - Criação de escritórios } \\
\text { especializados nacionais na } \\
\text { área de saúde pública, muitas } \\
\text { vezes vinculados aos ministérios } \\
\text { responsáveis pela aplicação das leis. } \\
\text { - Desenvolvimento inicial dos } \\
\text { esquemas de saúde previdenciária, } \\
\text { sob diferentes formas (fundos de } \\
\text { doença, sociedades de ajuda mútua } \\
\text { etc.), principalmente nos países } \\
\text { Brasil, Chile e Uruguai). }\end{array}$ & 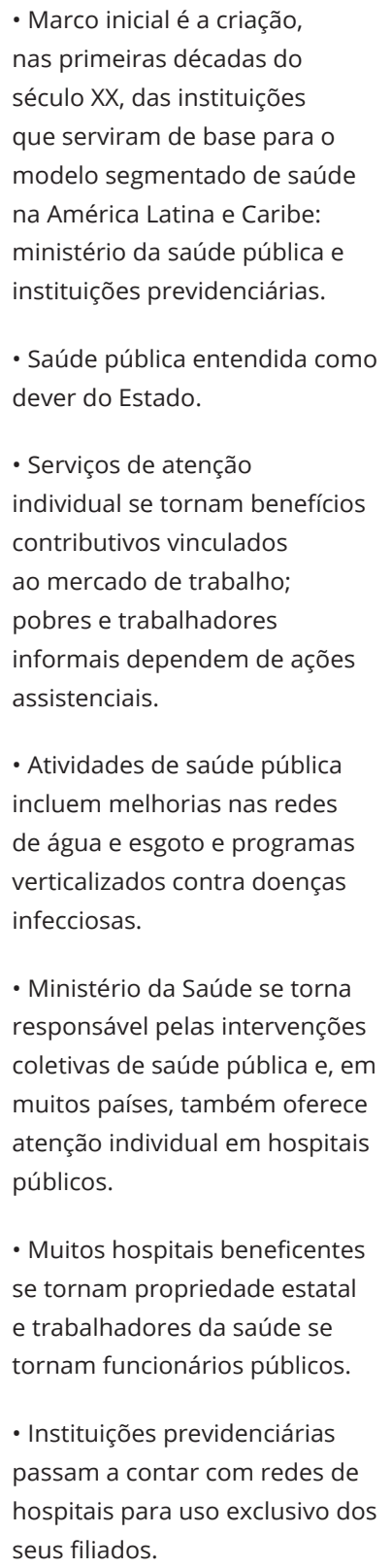 & $\begin{array}{l}\text { • Início marcado pela adoção de } \\
\text { legislação nacional no âmbito } \\
\text { da previdência social para criar } \\
\text { um segmento da população } \\
\text { que se encontra coberta pelos } \\
\text { benefícios contributivos e outro } \\
\text { segmento que está excluído. } \\
\text { • Dois movimentos simultâneos } \\
\text { no campo da atenção individual: } \\
\text { expansão dos serviços públicos } \\
\text { para a população pobre e } \\
\text { implantação de políticas para } \\
\text { aprofundar a segmentação } \\
\text { entre trabalhadores formais e } \\
\text { não assalariados e pobres. } \\
\text { e crescimento rápido dos } \\
\text { mospitais privados. } \\
\text { - Atividades de saúde pública } \\
\text { marcadas pela expansão da } \\
\text { atenção primária e pela inclusão } \\
\text { de serviços materno-infantis } \\
\text { e de planejamento familiar } \\
\text { aos programas de combate às } \\
\text { doenças transmissíveis. } \\
\text { verticais. }\end{array}$ & $\begin{array}{l}\text { - Início com a integração dos } \\
\text { serviços de saúde vinculados } \\
\text { ao sistema previdenciário } \\
\text { ao Ministério da Saúde ou } \\
\text { a introdução de ações para } \\
\text { equalizar os serviços oferecidos } \\
\text { nestes dois segmentos. } \\
\text { - Consenso crescente de que a } \\
\text { atenção à saúde é um direito } \\
\text { social, ligado à consolidação da } \\
\text { democracia. } \\
\text { - Mudanças demográficas e } \\
\text { epidemiológicas sinalizam } \\
\text { para a necessidade de ir além } \\
\text { das atividades de prevenção, } \\
\text { diagnóstico e tratamento } \\
\text { de doenças transmissíveis e } \\
\text { materno-infantis. }\end{array}$ \\
\hline
\end{tabular}

Fonte: adaptado de Coetler et al. 50 .

\section{Considerações finais}

A proteção social na América Latina e Caribe apresenta avanços e recuos ao longo do tempo, alternando períodos de ampliação da cobertura e maior atuação do Estado na área social com períodos de recuo parcial do Estado e adoção de políticas sociais minimalistas e focalizadas nos segmentos 
mais pobres da população. Apesar dos avanços observados no período recente, prevalecem modelos segmentados por classes sociais, grande participação de dispêndio privado e da oferta privada de serviços em muitos países (a despeito do caráter universal de algumas políticas sociais), manutenção de clientelas fechadas com sistemas próprios de proteção social (militares, por exemplo) e subsídios diversos para esquemas privados de acesso. Tais características são coerentes com o regime híbrido das políticas públicas na região 54,55, marcado pela adoção simultânea de políticas neoliberais, cujo ideário valoriza a sociedade mercantil e o autofinanciamento do acesso aos serviços (aumento da participação dos usuários no gasto social), e políticas mais intervencionistas, voltadas para reduzir as grandes diferenças materiais que caracterizam os países da região.

O caso da saúde ilustra bem as contradições e os limites desse modelo híbrido. A prevalência de sistemas segmentados de saúde, com acesso diferenciado para distintos grupos populacionais, mostra a dificuldade de formar coalizões progressistas suficientemente fortes para romper com arranjos institucionais profundamente enraizados na sociedade latino-americana, e implantar sistemas públicos universais baseados na noção de saúde como direito inerente à condição de cidadania. Se as experiências de resistência e confronto com a agenda neoliberal na saúde (Cuba, Costa Rica, Brasil e mais recentemente Bolívia, Venezuela e Uruguai) indicam a existência de alternativas para os países da região, elas também revelam sua fraqueza e fragilidade, na medida em que muitos países passaram a adotar a proposta de cobertura universal de saúde. Esse movimento sugere que a arena decisória da saúde na América Latina e Caribe (e no mundo) tem sido fortemente cooptada pela agenda neoliberal 56, seja pela adoção de inúmeras formas de privatização dos serviços, seja pela apropriação e reenquadramento de valores, saberes e práticas de diversos setores progressistas que atuam no campo da saúde coletiva e que defendem um modelo com mais justiça social e equidade.

\section{Colaboradores}

A. L. d'A. Viana participou da concepção, redação e revisão final. A. M. M. Fonseca contribuiu na concepção e redação do artigo. H. P. Silva colaborou na revisão da literatura, análise de dados e redação do artigo. 


\section{Referências}

1. Cecchini S, Filgueira F, Martínez R, Rossel C. Instrumentos de protección social: caminos latinoamericanos hacia la universalización. (LC/G.2644-P). Santiago: Comisión Económica para América Latina y el Caribe; 2015. (Libros de la CEPAL, 136).

2. Cecchini S, Filgueira F, Robles C. Social protection systems in Latin America and the Caribbean: a comparative view. Santiago: Comisión Económica para América Latina y el Caribe; 2014

3. Comisión Económica para América Latina y el Caribe. Social panorama of Latin America 2015. Santiago: Comisión Económica para América Latina y el Caribe; 2016.

4. Draibe SM, Riesco M. Estados de Bem-Estar Social e estratégias de desenvolvimento na América Latina. Um novo desenvolvimentismo em gestação? Sociologias 2011; 13: 220-54.

5. Bastos PPZ. A economia política do novodesenvolvimentismo e do social desenvolvimentismo. Economia e Sociedade 2012; 21(n. Esp.):779-810.

6. Viana ALD, Silva HP. Desenvolvimento e institucionalidade da política social no Brasil. In: Machado CV, Baptista TWF, Lima LD, organizadores. Políticas de saúde no Brasil: continuidades e mudanças. Rio de Janeiro: Editora Fiocruz; 2012. p. 31-60

7. Pochmann M. Nova classe media? O trabalho na base da pirâmide social. São Paulo: Boitempo; 2012.

8. Lavinas L. How social developmentalism reframed social policy in Brazil. Berlin: International Research Network on Interdependent Inequalities in Latin America; 2016. (Working Paper Series, 94).

9. Lo Vuolo RM. The limits of redistributive policies in Latin America: complementarities between economic and social protection systems. In: Fritz B, Lavinas L, editors. A moment of equality for Latin America: Challenges for redistribution. New York: Routledge; 2016. p. 31-52.

10. Organisation for Economic Co-operation and Development; Economic Commission for Latin America and the Caribbean; Development Bank of Latin America. Latin American economic outlook 2017: youth, skills and entrepreneurship. Paris: OECD Publishing; 2016.

11. Viana ALd'A, Silva HP. Brazilian social policy in times of crisis: on the road to a private liberal social model? Cad Saúde Pública 2015; 31:2471-4.

12. Mérrien F-X. L'État-providence. Paris: Presses Universitaires de France; 1997.

13. Di Giovanni G. Sistemas de proteção social: uma introdução conceitual. In: Oliveira MA, organizador. Reforma do Estado e políticas de emprego no Brasil. Campinas: Editora da Unicamp; 1998. p. 9-30.
14. Viana ALd'A, Levcovitz E. Proteção social: introduzindo o debate. In: Viana ALd'A, Elias PEM, Ibañez N, organizadores. Proteção social: dilemas e desafios. São Paulo: Editora Hucitec; 2005. p. 15-57.

15. Kuhnle S, Sander A. The emergence of the western Welfare State. In: Castles FG, Leibfried S, Lewis J, Obinger H, Pierson C, editors. The Oxford handbook of Welfare State. Oxford: Oxford University Press; 2010. p. 61-80.

16. Kerstezetzky CL. O estado do bem-estar social na idade da razão: a reinvenção do estado social no mundo contemporâneo. Rio de Janeiro: Elsevier; 2012.

17. Arretche MTS. Emergência e desenvolvimento do Welfare State: teorias explicativas. Boletim Informativo e Bibliográfico em Ciências Sociais 1995 ; 39:3-40.

18. Marchesi G. La evolución de la política económica y social en Argentina, Chile y Perú: una visión comparativa. Austin: Center for Latin American Social Policy, University of Texas at Austin; 2004.

19. Cohen E, Franco R. Gestión social: cómo lograr eficiencia e impacto en las políticas sociales. Coyoacán: Siglo XXI; 2005

20. Andrenacci L, Repetto F. Universalismo, ciudadanía y Estado en la política social Latinoamericana. Washington DC: Instituto Interamericano para el Desarrollo Social; 2006.

21. Mesa-Lago C. History of social security in Latin America. In: International Meeting on the History of Insurance Companies in the World. Madrid: Fundación Mapfre; 2008. p. 1-16.

22. Cecchini S, Martínez R. Protección social inclusiva en América Latina: una mirada integral, un enfoque de derechos. Santiago: Comisión Económica para América Latina y el Caribe; 2011.

23. Filgueira F. Modelos de desarrollo, matriz del Estado social y herramientas de las políticas sociales latinoamericanas. In: Cecchini S, Filgueira F, Martínez R, Rossel C, editores. Instrumentos de protección social: caminos latinoamericanos hacia la universalización. Santiago: Comisión Económica para América Latina y el Caribe; 2015. p. 49-84.

24. Prebisch R. Dinâmica do desenvolvimento latino-americano. Rio de Janeiro: Fundo de Cultura; 1964

25. Furtado C. Subdenvolvimento e estagnação na América Latina. 3a Ed. Rio de Janeiro: Editora Civilização Brasileira; 1968.

26. Santos WG. Cidadania e justiça: a política social na ordem brasileira. 2a Ed. Rio de Janeiro: Campus; 1987.

27. Mattos RA. As agências internacionais e as políticas de saúde nos anos 90: um panorama geral da oferta de ideias. Ciênc Saúde Coletiva $2001 ; 6: 377-89$ 
28. Fonseca AMM, Viana ALd'A. Direito à saúde, atenção básica e transferências condicionadas de renda na América Latina. Ciênc Saúde Coletiva 2007; 12:1505-12.

29. Esping-Andersen G. The three worlds of welfare capitalism. Cambridge: Polity Press; 1990.

30. Titmuss RM. Essays on the Welfare State. Surrey: Unwin Brothers; 1963.

31. Arts WA, Gelissen J. Models of Welfare State. In: Castles FG, Leibfried S, Lewis J, Obinger $\mathrm{H}$, Pierson C, editors. The Oxford handbook of Welfare State. Oxford: Oxford University Press; 2010. p. 569-83.

32. Ferragina W, Seeleib-Kaiser M. Welfare regime debate: past, present, futures? Policy \& Politics 2011; 39:583-611.

33. Ebbinghaus B. Comparing welfare state regimes: are typologies an ideal or realistic strategy? In: European Social Policy Analysis Network: ESPAnet Conference. http://www.cas. ed.ac.uk/__data/assets/pdf_file/0005/89033/ Ebbinghaus_-_Stream_2.pdf (acessado em Nov/2016).

34. Fleury S, Molina CG. Modelos de protección social. Washington DC: Instituto Interamericano para el Desarrollo Social; 2002.

35. Del Valle AH. Comparando regímenes de bienestar en América Latina. Rev Eur Estud Latinoam Caribe 2010; 88:61-76.

36. Andrade FF. Regimes de proteção social na América Latina: modelos e tendências recentes. Emancipação 2012; 12:21-32.

37. Cantu R. Depois das reformas: os regimes de proteção social latino-americanos na década de 2000. Revista de Sociologia e Política 2015; 23:45-73.

38. Mesa-Lago C. Comparative study of the development of social security in Latin America. Int Soc Secur Rev 1986; 39:127-52.

39. Filgueira F. El nuevo modelo de prestaciones sociales en América Latina: residualismo y ciudadania estratificada. In: Roberts B, organizador. Ciudadania y política social. San José: Facultad Latinoamericana de Ciencias Sociales/ Indian Social Science Research Council; 1998. p. 82-115

40. Franzoni JM. Welfare regimes in Latin America: capturing constellations of markets, families and policies. Lat Am Polit Soc 2008; 50:67-100.

41. Uthoff A, Vera C, Ruedi N. Relación de dependencia del trabajo formal y brechas de protección social en América Latina y el Caribe. Santiago de Chile: Comisíon Económica para América Latine y el Caribe; 2006. (Financiamiento del Desarrollo Series, 169).

42. Barrientos A. Latin America: towards a liberalinformal welfare regime. In: Gough I, Wood G, editors. Insecurity and welfare regimes in Asia, Africa and Latin America. Cambridge: Cambridge University Press; 2004. p. 121-68.
43. Mesa-Lago C. Social security in Latin America: pressure groups, stratification and inequality. Pittsburgh: University of Pittsburgh Press; 1978.

44. Roemer MI. Medical care and social class in Latin America. Milbank Mem Fund Q 1964; 42:54-64.

45. Londoño JL, Frenk J. Structured pluralism: towards an innovative model for health system reform in Latin America. Health Policy 1997; 41:1-36.

46. Herediaa N, Laurell AC, Feoc O, Noronha J, González-Guzmáne R, Torres-Tovar M. The right to health: what model for Latin America? Lancet 2015; 385:e34-7.

47. Frenk J. Leading the way towards universal health coverage: a call to action. Lancet 2015 ; 385:1352-8

48. Andrade LOM, Pellegrini Filho A, Solar O, Rigoli F, Salazar LM, Serrate PCF, et al. Social determinants of health, universal health coverage, and sustainable development: case studies from Latin American countries. Lancet 2015; 385:1343-51.

49. Mesa-Lago C. Reassembling social security: a survey of pensions and health care reforms in Latin America. New York: Oxford University Press; 2008.

50. Cotlear D, Gómez-Dantés O, Knaul F, Atun R, Barreto ICHC, Cetrángolo O, et al. Overcoming social segregation in health care in Latin America. Lancet 2015; 385:1248-59.

51. Laurell AC. Sistemas universales de salud: retos y desafíos. Quito: Instituto Suramericano de Gobierno en Salud, Unión de Naciones Suramericanas; 2012.

52. Noronha JC. Universal health coverage: how to mix concepts, confuse objectives, and abandon principles. Cad Saúde Pública 2013; 29:847-9.

53. Ocké-Reis CO. Cobertura universal de saúde: inclusão ou exclusão? Boletim de Análise Política Institucional IPEA 2016; 9:19-26.

54. Ban C. Brazil's liberal neo-developmentalism: new paradigm or edited orthodoxy? Rev Int Polit Econ 2013; 20:298-331.

55. Sallum Jr. B, Goulart JO. O Estado brasileiro contemporâneo: liberalização econômica, política e sociedade nos governos FHC e Lula. Revista de Sociologia e Política 2016; 24:11535.

56. Birn A-E, Nervi L, Siqueira E. Neoliberalism redux: the global health policy agenda and the politics of cooptation in Latin America and beyond. Dev Change 2016; 47:734-59. 


\section{Abstract}

Recent studies suggest that governments in the majority of Latin American and Caribbean countries were able to expand social investments and introduce innovations in social protection policies in the last two decades with positive results in the actions' coverage and impact. However, the restrictions imposed by the current fiscal crisis and the rise of governments more ideologically aligned with the neoliberal discourse in various countries in the region point to a new retreat of the state from the social area, thereby compromising recent advances. The article aims to discuss the changes, contradictions, and limits of recent social protection standards in Latin America and the Caribbean. The discussion includes three items: a description of the history of social protection in the region, seeking to identify its principal historical periods and characteristics (benefits, target public, and financing); the social protection models that have been implemented in the region; and the specific case of health. We argue that although countries have adopted different solutions in the field of social protection, the policies' hybrid nature (with extensive private sector participation in the financing, supply, and management of services) and the prevalence of segmented models (with differential access according to individuals' social status) have been predominant traits in social protection in Latin America and the Caribbean, thus limiting the possibilities for greater equity and social justice.

Delivery of Health Care; Public Policy; Latin America; Caribbean

\section{Resumen}

Estudios recientes sugieren que los gobiernos de la mayoría de los países de Latinoamérica y Caribe fueron capaces de ampliar sus inversiones sociales e introducir innovaciones en las politicas de protección social durante las dos últimas décadas, con resultados positivos en términos de cobertura e impacto de las acciones. No obstante, las restricciones impuestas por el actual escenario de crisis fiscal, además de la ascensión de gobiernos ideológicamente más alienados con el discurso neoliberal en diversos países de la región, apuntan a una nueva retirada del Estado en el área social, comprometiendo los avances obtenidos recientemente. El objetivo de este trabajo es discutir los cambios, contradicciones y limites de los patrones recientes de protección social en Latinoamérica y Caribe. La discusión se realiza sobre tres items: descripción de la trayectoria de la protección social en la región, buscando identificar los principales periodos y características de la protección social (beneficios, público-objetivo y financiación); los modelos de protección social históricamente implantados; y el caso de la salud. Argumentamos que, aunque los diferentes países hayan adoptado soluciones diferenciadas en el campo de la protección social, el carácter híbrido de las politicas (con gran participación del sector privado en la financiación, oferta y gestión de los servicios) y la prevalencia de modelos segmentados (con acceso diferenciado, en función de la posición social de los individuos) han sido las características predominantes de la protección social en Latinoamérica y Caribe, limitando las posibilidades de una mayor equidad y justicia social.

Prestación de Atención de Salud; Política Pública; América Latina; Caribe
Recebido em 21/Dez/2016

Versão final reapresentada em 07/Mar/2017

Aprovado em 08/Mar/2017 